\title{
A PIEZOELECTRIC MICROPUMP BASED ON MICROMACHINING OF SILICON
}

\author{
H. T. G. VAN LINTEL
}

CME Twente, P.O. Box 545, 7500 AM Enschede (The Netherlands)

F. C. M. VAN DE POL* and S. BOUWSTRA

University of Twente, P.O. Box 217, 7500 AE Enschede (The Netherlands)

(Received August 10, 1987, in revised form February 25, 1988; accepted March 17, 1988)

\begin{abstract}
The design and realization of two pumps based on micromachining of silicon are described. The pumps, which are of the reciprocating displacement type, comprise one or two pump chambers, a thin glass pump membrane actuated by a piezoelectric disc and passive silicon check valves to direct the flow. Chambers, channels and valves are realized in a silicon wafer by wet chemical etching. The results of mechanical calculations and simulations show good agreement with the actual behaviour of the pumps. It is possible to design pumps having a specific yield and pressure dependence, and which are fail-safe (the flow is blocked while the pump is switched off).
\end{abstract}

\section{Introduction}

Since 1983 research has been carried out at the University of Twente, within the Transducers and Materials Science Group, on the possibility of realizing a micropump based on micromachining of silicon and thin-film techniques. Silicon technology provides unique technical possibilities and silicon shows excellent properties as a mechanical material in sensors and actuators [1].

Starting from the principle of a peristaltic piezoelectric fluid pump, developed in 1980 at Standord University by Smits [2], several prototypes were realized in silicon wafers. The demand for more reproducible, more stable and better pump behaviour led to a new design, which will be discussed in this paper.

\footnotetext{
*Author to whom correspondence should be addressed.
} 


\section{Design and working principle}

We have designed a two-valve and a three-valve pump, both having a glass/silicon/glass sandwich structure. Figure 1(a) shows a cross-section of the two-valve pump, comprising a pump chamber, a piezoelectric disc/glass double-layer pump membrane and two passive silicon check valves that can seal a passage.

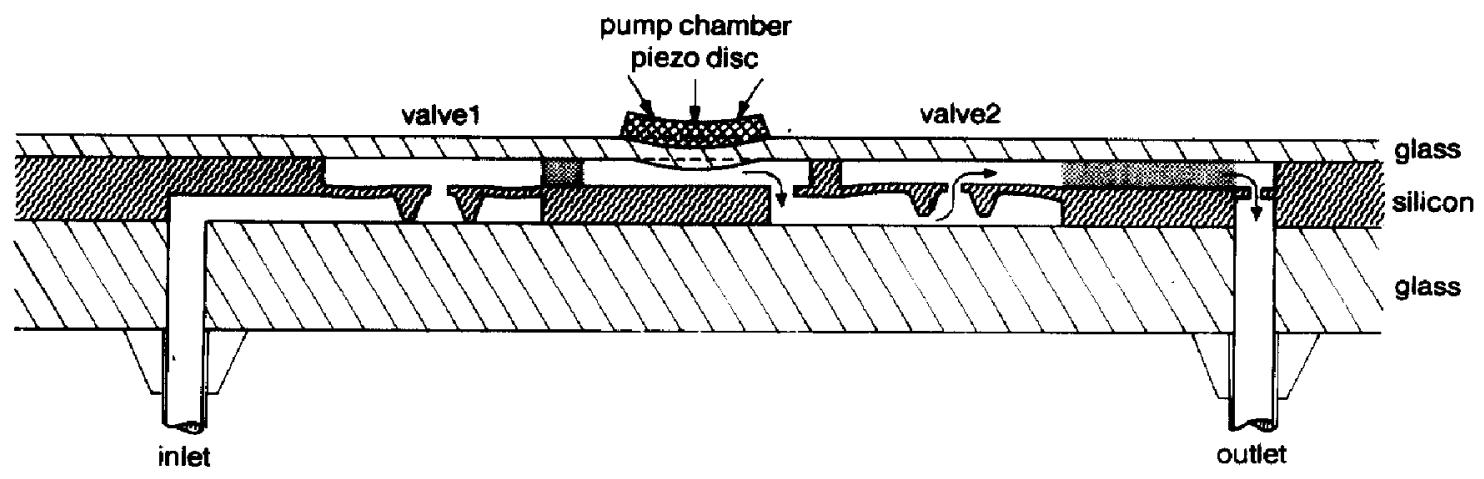

(a)



(b)

Fig. 1. Sketches of the pumps: (a) two-valve pump; (b) three-valve pump.

The application of an electric voltage over the piezoelectric disc (from here on referred to as the 'piezo disc') causes the double layer to bend downwards. The volume of the pump chamber decreases and the liquid is forced through valve 2 to the outlet, while valve 1 checks the return flow to the inlet. When the voltage is switched off, the membrane will adopt its original shape and fluid will be drawn through valve 1 while at the same time valve 2 will check the return flow from the outlet. The yield of this two-valve pump is strongly dependent on the outlet pressure and, in the case of excess pressure at the inlet, both valves will open and allow liquid to pass continuously.

In the three-valve pump an extra valve is added, see Fig. 1(b). This third valve is connected to the inlet by means of a channel and closes the outlet when the inlet pressure exceeds that of the outlet. Moreover, the dependence of the yield on the pressure can be reduced to a minimum with this third valve. Hence, this three-valve pump is fail-safe and the yield is pressure 
independent in a specific working range. This will be clarified in the next section.

\section{Components}

For the model of the pump, expressions are derived in this section for the free volume stroke of the piezo disc/glass pump membrane under an applied block voltage. More expressions are also derived for the deflections and the volume strokes of the pump membrane and the valve diaphragms, due to net pressures. Further, the effect of a thin oxide film on the pretension of a valve is determined, and assuming a laminar flow across the sealing ring, we can estimate the restriction to the flow through the small gap when a valve is opened.

The theory of bending of plates [3] is used to determine the required expressions for the pump membrane and the valve diaphragms. The elastic behaviour of single-crystal silicon is anisotropic: Young's modulus $E$, Poisson's ratio $\nu$ and the shear modulus depend on the direction in the (100)plane of the plate [5], as also does the flexural rigidity $D=E /\left(1-\nu^{2}\right) \times h^{3} / 12$ for the plate with thickness $h$. We can define an approximate effective value of the flexural rigidity $D=E^{\prime} h^{3} / 12$, with $E^{\prime}=1.55 \times 10^{11} \mathrm{~N} / \mathrm{m}^{2}$ the modified Young's modulus [4]. With this effective flexural rigidity, we can make use of the differential equations for the deflection of the plates due to a circumferential bending moment, a circumferential force or a pressure difference, as described in ref. 3. Integration, taking discontinuities of the plate thickness into account, yields expressions for the deflections due to the described loads. Superposition, and accounting for the boundary conditions, then leads to the expressions for the deflection due to the particular combination of loads. Further integration yields the expressions for the volume stroke for the considered loading case.

\section{Pump membrane}

The diameter of the piezo disc is smaller than that of the glass membrane. When a voltage $U$ is applied over the piezo disc, the electric field $E_{3}=$ $-U / t$, with $t$ the thickness of the piezo disc, forces the disc to shrink in the radial direction, with a free strain $\epsilon=d_{31} E_{3}$, where $d_{31}$ is the piezoelectric constant for the 3-1 coupling. This causes a lateral tensile stress $\sigma$ in the piezo disc, and a bending moment $M=\sigma t h_{\mathrm{g}} / 2$ in the piezo disc/glass-double layer, forcing the pump membrane to bend downward. $h_{\mathrm{g}}$ is the thickness of the glass. For small deflections we find for the free volume stroke:

$\Delta V_{\text {piezo }}=\gamma_{1} d_{31} U d^{4} / t^{2}$

with $\Delta V_{\text {piezo }}$ the free volume stroke of the pump membrane actuated by the piezo disc; $d_{31}$ the piezoelectric constant for the 3-1 coupling; $U$ the applied voltage; $d$ the diameter of the piezo disc; $t$ the thickness of the piezo disc; 
and $\gamma_{1}$ a dimensionless parameter depending on ratios of geometries and material properties of the piezo disc and the glass membrane.

An induced pressure $p$ will reduce the actual volume stroke by an amount $p \Delta v_{\text {memb }}$, where $\Delta v_{\text {memb }}$ is the volume stroke of the membrane under a unit net pressure:

$\Delta v_{\text {memb }}=\gamma_{2} d^{6} /\left(E t^{3}\right)$

with $E$ the Young's modulus of the piezo disc and $\gamma_{2}$ a parameter analogous to $\gamma_{1}$ in eqn. (1).

A maximum volume stroke of the pump membrane in the considered pressure range is obtained for a diameter ratio piezo disc/glass membrane of 0.8 . The piezo disc should be as thin as possible, with its thickness limited by the breakdown voltage.

\section{Valves}

Each valve consists of a circular silicon diaphragm, which forms a seal on the lower glass wafer when the valve is closed. The diaphragm consists of a flexural outer ring and a rigid sealing ring. Each valve has a thin oxide film on the summit of its sealing ring.

Due to the flexibility of the outer ring, a net pressure $\Delta p$ acting on a valve deflects the sealing ring. This deflection $\delta$ may be written as

$\delta=\Delta p \gamma_{3} w^{4} /\left(E^{\prime} h^{3}\right)$

with $\delta$ the deflection of the valve; $\Delta p$ the net pressure acting on the valve; $w$ the width of the outer ring; $E^{\prime}$ the modified Young's modulus of silicon; $h$ the thickness of the diaphragm; and $\gamma_{3}$ a dimensionless parameter depending on the dimensions of the sealing ring and of the flexural outer ring.

Also, the outer ring itself will bulge out under a net pressure, with a volume stroke $p \Delta v_{\text {valve }}$ where $\Delta v_{\text {valve }}$ is the volume stroke of the outer ring under a unit net pressure:

$\Delta v_{\text {valve }}=\gamma_{4} w^{6} /\left(E^{\prime} h^{3}\right)$

with $\gamma_{4}$ a parameter analogous to $\gamma_{3}$ in eqn. (3).

The thin oxide film on the summit of the sealing ring deflects the diaphragm slightly when the valve is closed. This gives the valve a small pre-

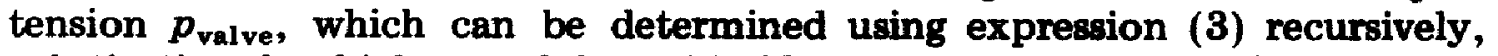
substituting the thickness of the oxide film $h_{0}$ for the deflection $\delta$.

In the three-valve pump the oxide film also covers part of the flexural outer ring of valve 3 . In this case the compressive stress $\sigma_{0}$ in the oxide film [6] induces a bending moment in the silicon diaphragm, with a corresponding free deflection $\delta^{\prime}$ :

$\delta^{\prime}=\sigma_{0} \gamma_{5} h_{0} w^{2} /\left(E^{\prime} h^{2}\right)$

with $\sigma_{0}$ the compressive stress in the oxide film; $h_{0}$ the thickness of the oxide film; and $\gamma_{5}$ a dimensionless parameter depending of the geometry of the valve and the radius of the oxide film. 
The pre-tension of valve 3 can be determined using expression (3) recursively again, substituting the sum of $h_{0}$ and $\delta^{\prime}$ for the deflection $\delta$.

When a valve is opened, the gap between the sealing ring and the glass plate forms a restriction to the flow. Assuming a laminar flow through this gap, we can derive the following expression:

$\phi=\gamma_{6} \Delta p \delta^{3} / \mu$

with $\phi$ the volume flow through the gap; $\Delta p$ the pressure difference across the gap; $\delta$ the deflection of the sealing ring; $\mu$ the viscosity of the fluid; and $\gamma_{6}$ a dimensionless parameter depending on the ratio of the radius and the width of the sealing ring.

Restrictions to the flow through the connecting channels were found to be negligible compared to the above effect. It was further assumed that other contributions to the restriction could also be neglected and that leakage through closed valves is zero. The last assumption is validated by leak-rate measurements (Section 7).

\section{Pumping mechanism}

The piezo disc is subjected to a periodic block voltage. For the pump membrane we can distinguish a downward stroke and an upward stroke.

\section{Two-valve pump}

When the pump membrane is activated downwards, the pressure in the pump chamber is increased. Provided this pressure exceeds the sum of the outlet pressure and the pre-tension of valve 2, the latter valve will open. Due to the pressure difference across the gap underneath the sealing ring, the fluid will flow through this gap, thereby reducing this difference. After a short period the chamber pressure will equal the sum of the pre-tension of valve 2 and the outlet pressure, and the valve will close, see Fig. 2(a).

When the voltage is switched off, the pump membrane moves upwards, causing a pressure decrease in the pump chamber. Valve 1 opens, and the fluid flows into the pump chamber until the chamber pressure equals the inlet pressure minus the pre-tension of valve 1, see Fig. 2(b).

The total pumped volume $\Delta V$ can be found from the difference between the volume of the pump chamber at the end of the downward stroke, and at the end of the upward stroke. The following expression results for $\Delta V$ :

$$
\begin{aligned}
\Delta V= & \Delta V_{\text {piezo }}-\left(p_{\text {out }}-p_{\text {in }}+p_{\text {valve 1 }}+p_{\text {valve 2 }}\right) \\
& \times\left(\Delta v_{\text {memb }}+\Delta v_{\text {valve } 1}+\Delta v_{\text {valve 2 }}\right)
\end{aligned}
$$

From eqn. (7) it can be seen that the total pumped volume can be regarded as the free volume stroke of the piezo disc/glass pump membrane due to the applied voltage, reduced by a lost volume, due to the bulging of the flexural parts under the induced pressures. From eqn. (4) it can be seen 


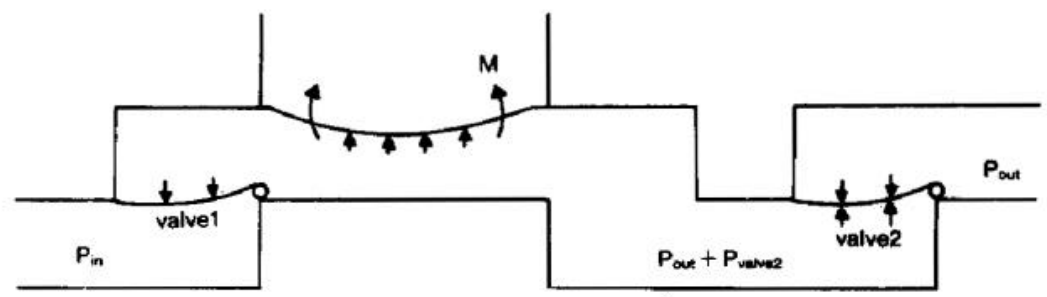

(a)

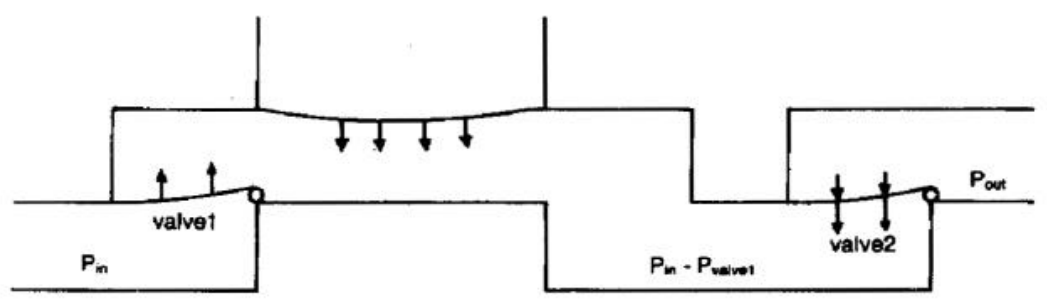

(b)

Fig. 2. Operation of the two-valve pump. (a) Situation at the end of the downward stroke. (b) Situation at the end of the upward stroke.

that the use of smaller and thicker valves leads to a reduction of this lost volume. However, the deflection due to an applied pressure will also be reduced according to eqn. (3). Expression (6) shows that this results in a decrease of the flow. The actual pump behaviour is predicted with the aid of simulations (Section 5).

Apparently, the outlet pressure can have a large influence on the total pumped volume. Also, if $p_{\text {out }}-p_{\text {in }}$ is negative and exceeds $p_{\text {valve } 1}$ and $p_{\text {valve 2 }}$. both valves will open, permitting a continuous flow.

\section{Three-valve pump}

This pump consists of two pump chambers, 1 and 2 . At the end of the downward stroke, the pressure in chamber 2 equals the sum of the pretension of valve 3 , the inlet pressure and the effect of the outlet pressure on the deflection of the sealing ring. The pressure in chamber 1 equals the sum of the pressure in chamber 2 and the pre-tension of valve 2, see Fig. 3(a). At the end of the upward stroke, the pressure in chamber 1 compensates the pre-tension of valve 1 minus the inlet pressure, see Fig. 3(b).

Expressions can be derived for the volume changes of chambers 1 and 2. During the upward stroke, valves 2 and 3 remain closed. For an incompressible fluid this implies that the volume of chamber 2 has not changed. Equating the expressions for this volume at the end of the downward stroke and at the end of the upward stroke yields the pressure in chamber 2. With this, the volume of chamber 1 at the end of the upward stroke can be determined.

Again, the total pumped volume in a complete cycle equals the difference between the volume of chamber 1 at the end of the downward stroke and at the end of the upward stroke. This results in an expression similar to eqn. (7) for the total pumped volume $\Delta V$ : 


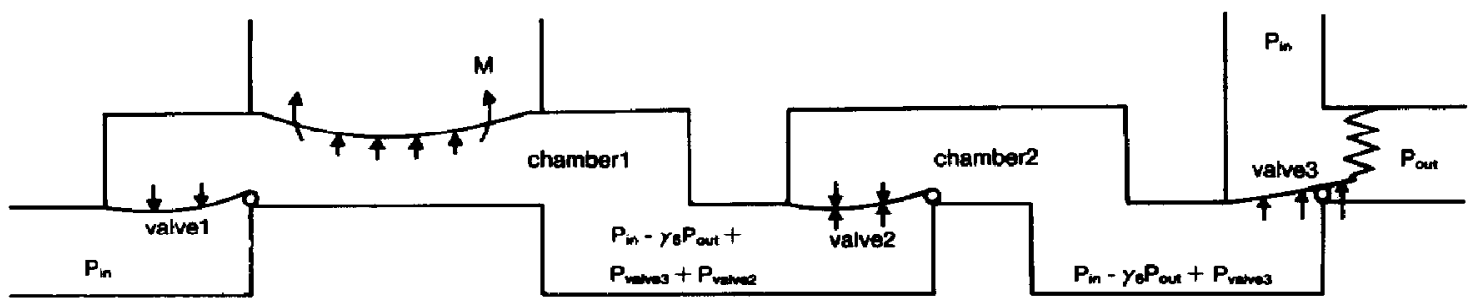

(a)

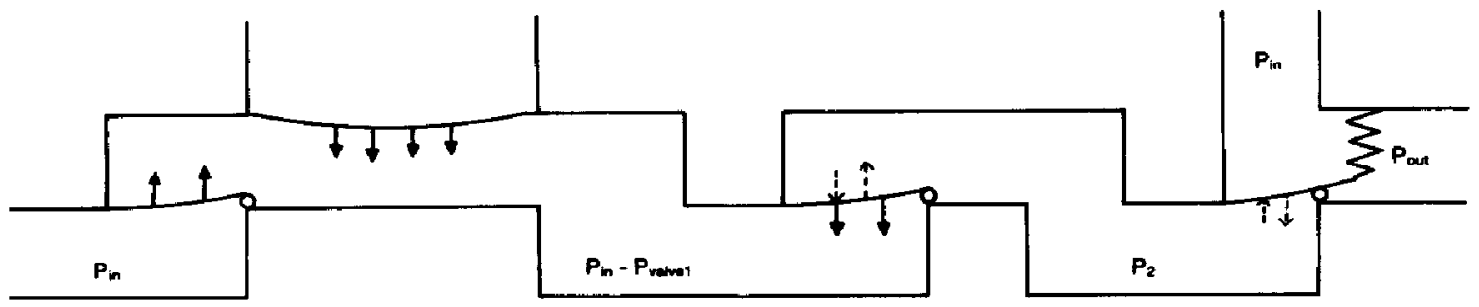

(b)

Fig. 3. Operation of the three-valve pump. (a) Situation at the end of the downward stroke. (b) Situation at the end of the upward stroke.

$$
\begin{aligned}
\Delta V= & \Delta V_{\text {piezo }}-\left(p_{\text {valve } 1}+p_{\text {valve 2 }}+p_{\text {valve 3 }}-\gamma_{7} p_{\text {out }}\right) \\
& \times\left(\Delta v_{\text {memb }}+\Delta v_{\text {valve } 1}+1 /\left(1 / \Delta v_{\text {valve } 2}+1 / \Delta v_{\text {valve 3 }}\right)\right)
\end{aligned}
$$

with $\gamma_{7}$ a dimensionless parameter, representing the effect of the outlet pressure on valve 3 , and depending on the ratio of the outer diameter of the sealing ring and the width of the flexural outer ring. Values of $\gamma_{7}$ less than 1 can be obtained, as the outlet pressure $p_{\text {out }}$ acts only on part of valve 3 .

It can be seen from expression (8) that for the three-valve pump valves 2 and 3 appear as two series capacitances. With the outlet pressure acting only on part of valve 3 , the influence of this pressure on the total pumped volume can be reduced to a minimum. Also, with the outlet pressure acting on the same side of the valve as the pressure of pump chamber 2, the influence of the outlet pressure on the pumped volume is, in fact, positive. For a certain value of $p_{\text {out }}$, valve 3 will be open permanently, and the performance of the three-valve pump will resemble that of the two-valve pump, with valve 3 serving as a mere restriction to the flow.

\section{Simulation}

A simulation of the pump operation has been carried out with TUTSIM, a simulation program developed at the University of Twente. For convenience, expressions (1) and (2) were rewritten in the form

$U(t)=a \Delta p(t)+b \Delta V(t)$

with $U(t)$ the voltage applied across the piezo disc; $\Delta p(t)$ the induced pressure difference across the pump membrane and $\Delta V(t)$ the induced volume stroke of the pump membrane. 
This formula shows the functioning of the pump membrane as providing a combination of a volume stroke and an induced pressure change. Formula (9) covers both the case of a free volume stroke when no pressure change is induced (1), and the case of bulging of the pump membrane due to a net pressure $\Delta p$, at constant voltage (2).

In the simulation diagram in Fig. 4 for the two-valve pump, a clock function and an amplifier generate the block voltage $U(t)$. A second amplifier transforms this into an induced pressure change $\Delta p$, while a third amplifier corrects this pressure for the bulging of the flexural parts of the closed valves. Finally, the effective pressure acting on valve 2 is obtained by subtracting the pre-tension of valve 2 and the outlet pressure. If this is positive, the valve opens. A fourth amplifier corrects the pressure to account for the bulging of the whole diaphragm of valve 2 and transforms this into the deflection $\delta$ of valve 2. A power raiser and a fifth amplifier determine the restriction to the flow, which is multiplied by the corrected net pressure over the valve to obtain the volume flow. Integration yields the total volume pumped through valve 2 . This volume is also fed back, via a sixth amplifier, to the second to account for the partial release of the pressure in the pump chamber, according to formula (8). This is repeated until the voltage is switched back to zero. In this new situation, with a negative induced pressure in the pump chamber, a similar process starts for determining the flow through valve 1 . Figure 5 shows some typical simulation results.

In the simulation diagram of the three-valve pump, additional blocks were used to account for the effect of the third valve. The diagram is then more complicated than the one described above. The principle, however, is similar and therefore we have omitted this diagram.

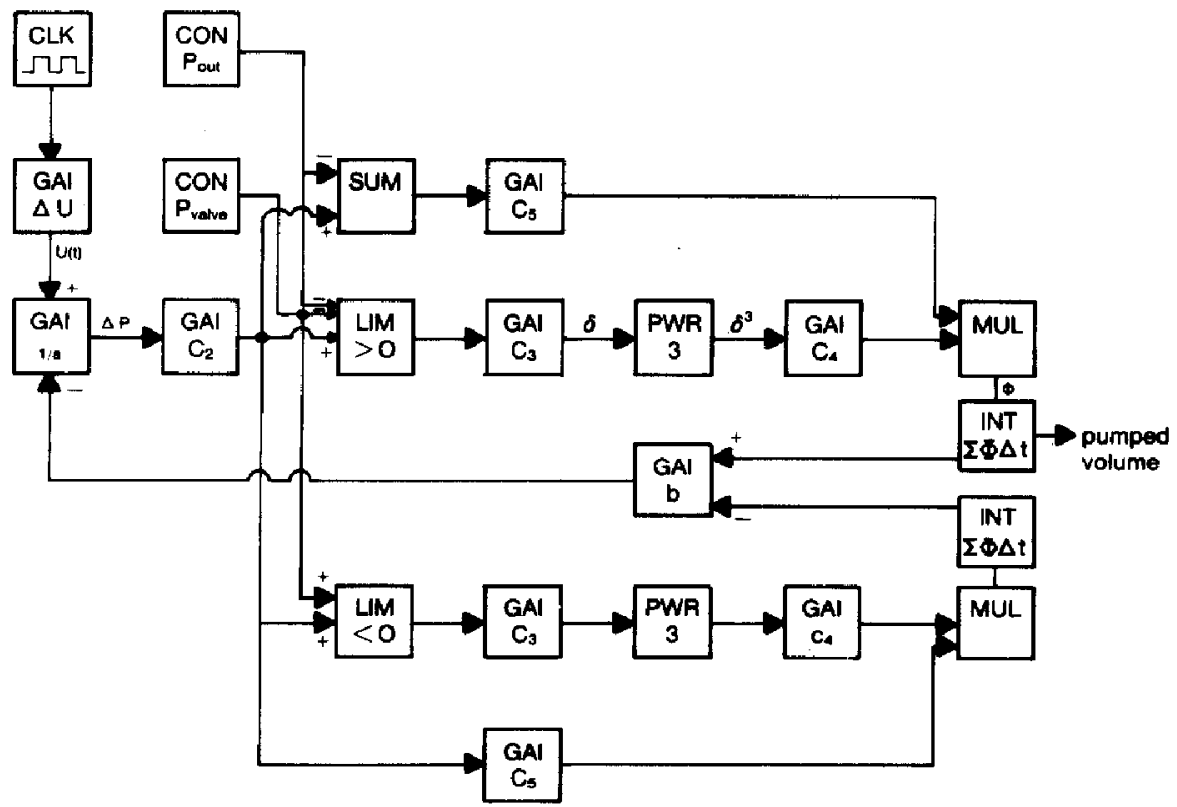

Fig. 4. Simulation diagram of the two-valve pump. 


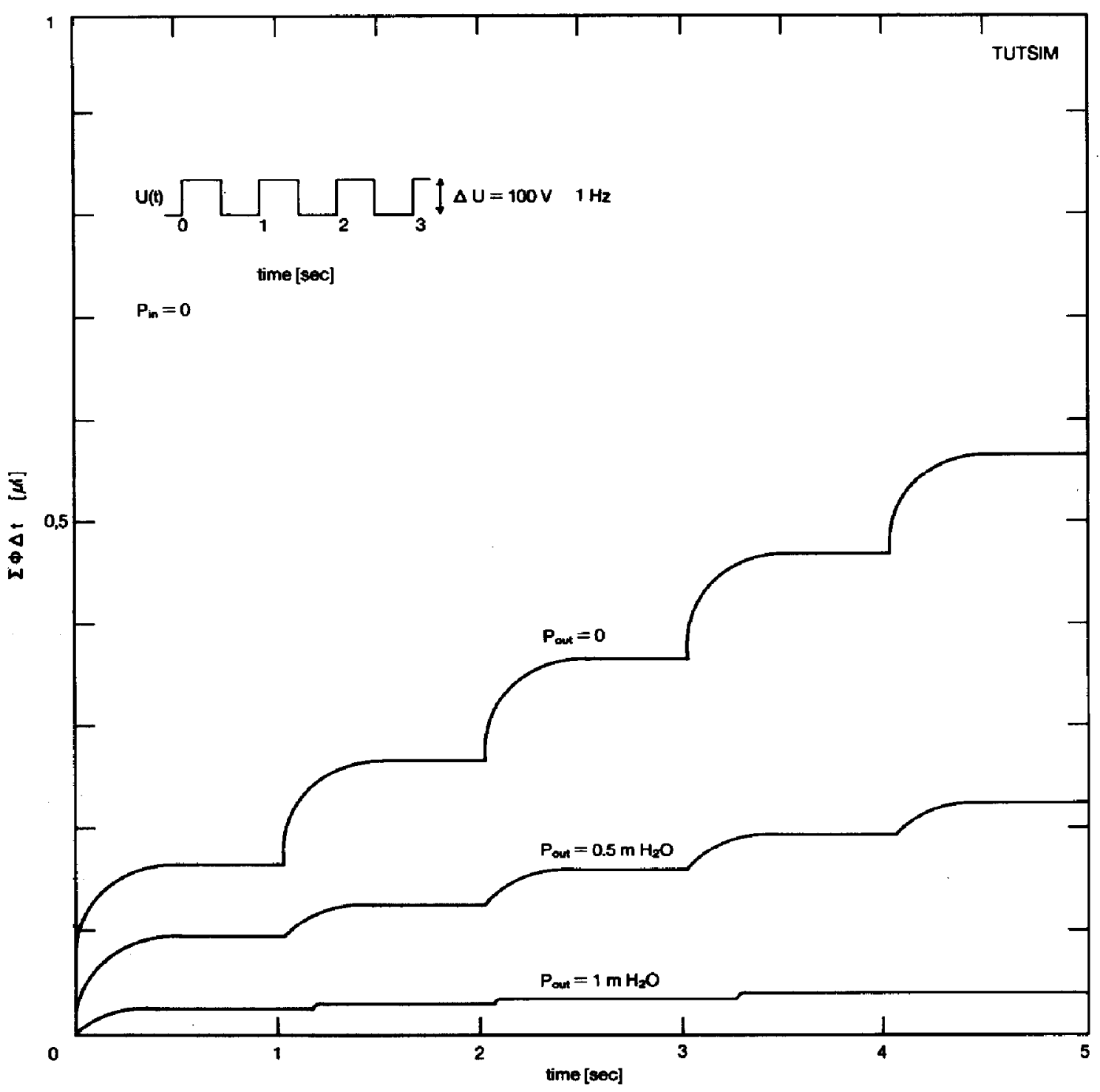

Fig. 5. Simulation results of the two-valve pump.

\section{Realization}

Table 1 lists the materials used in the realization of the described pumps. The holes and channels in the silicon wafer are etched by a solution of ethylene diamine, pyrocatechol and pyrazine in water (EDP) [7]. Silicon oxide was used as a mask material. This method ensures that flat diaphragms can be etched giving well-defined edges. The etching process being anisotropic, the diaphragms are actually facetted, but for the simulations they can be regarded as circular.

A sketch of the finished wafer is given in Fig. 6(a). The oxide mask for EDP-etching and the local oxide on the valves are obtained by oxidizing the water in a water/nitrogen atmosphere and selective oxide etching with a $\mathrm{HF} / \mathrm{NH}_{\mathbf{4}} \mathrm{F}$ solution. 
TABLE 1

Materials used for the described pumps

\begin{tabular}{|c|c|c|}
\hline Silicon wafer & Glass plates & Piezo disc \\
\hline \multirow{3}{*}{$\begin{array}{l}\text { (100)-wafer } \\
\text { polished both sides, } \\
\text { p-type (boron), } \\
\text { diameter } 2^{\prime \prime} \\
\text { thickness } 300 \mu \mathrm{m}\end{array}$} & $\begin{array}{l}\text { polished boron silicate glass } \\
\text { diameter } 2 \text { " }\end{array}$ & $\begin{array}{l}\text { 2-valve pump: } \\
\text { type, PXE-5 Philips, }\end{array}$ \\
\hline & $\begin{array}{l}\text { bottom plate, } \\
\text { thickness } 1.6 \mathrm{~mm}\end{array}$ & $\begin{array}{l}\text { diameter } 10 \mathrm{~mm} \text {, } \\
\text { thickness } 0.20 \mathrm{~mm} \text {. }\end{array}$ \\
\hline & $\begin{array}{l}\text { top plate, } \\
\text { 2-valve pump: } \\
\text { thickness } 0.19 \mathrm{~mm} \\
\text { 3-valve pump: } \\
\text { thickness } 0.3 \mathrm{~mm}\end{array}$ & $\begin{array}{l}\text { 3-valve pump: } \\
\text { type, PXE-52 Philips, } \\
\text { diameter } 10 \mathrm{~mm} \text {, } \\
\text { thickness } 0.11 \mathrm{~mm} \text {. }\end{array}$ \\
\hline
\end{tabular}
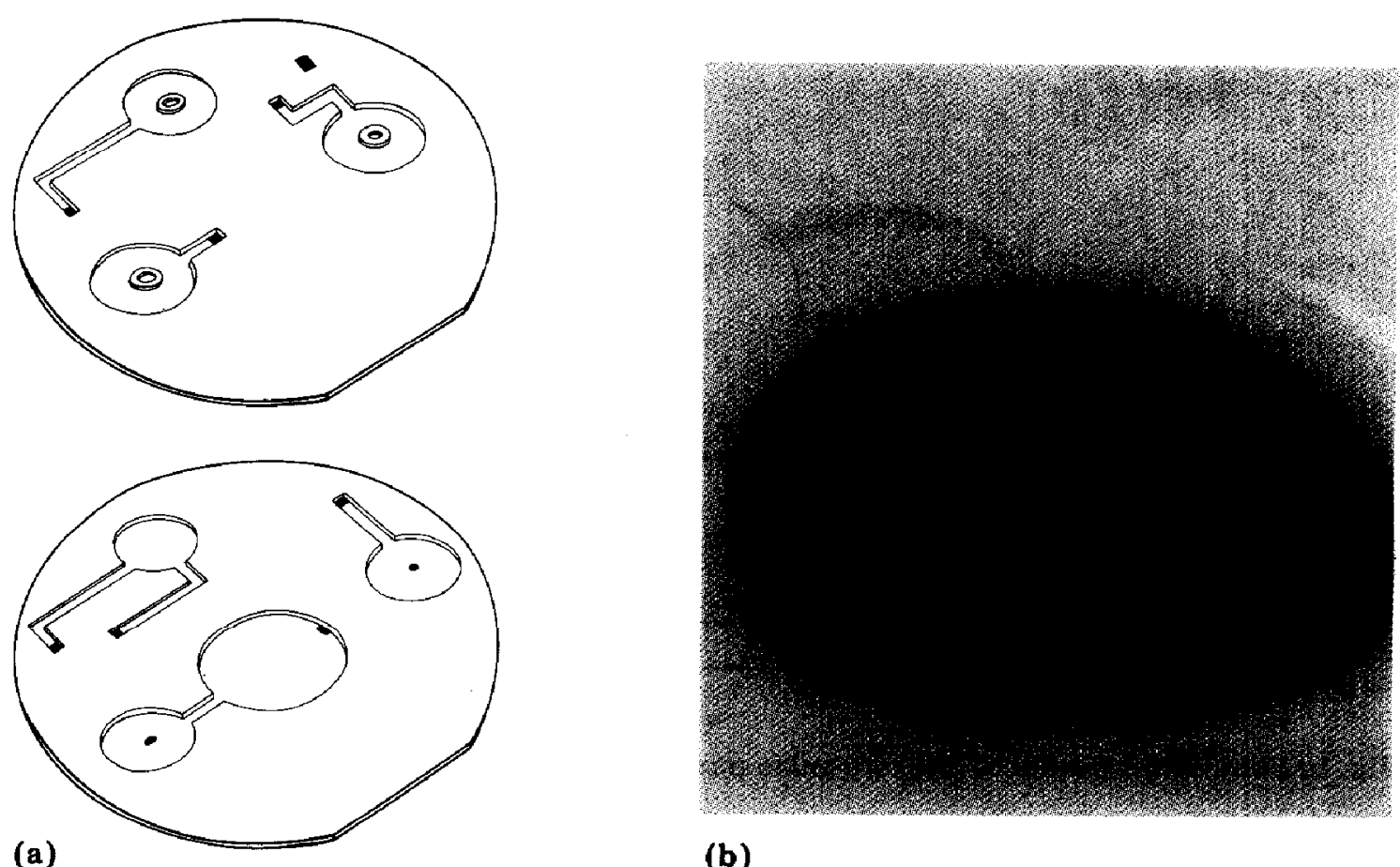

(b)

Fig. 6. Three-valve pump. (a) Treated silicon wafer. (b) Photo of asgembled pump.

The adhesion between the glass and the silicon is obtained by applying a technique known as anodic bonding $[8,9]$. After placing the wafer and glass plate between two electrodes and heating them up to $300{ }^{\circ} \mathrm{C}$, a voltage of $500 \mathrm{~V}$ is applied across the electrodes, resulting in a hermetic joint between the glass and silicon. The second glass plate is attached in the same manner. The oxide on the valves not only provides them with a pre-tension, but also prevents the valves becoming attached to the glass (selective bonding). The thermal expansion of both the particular type of glass used and the silicon, after heating from 20 to $300{ }^{\circ} \mathrm{C}$, is the same. Hence a bonding tem- 
perature of $300{ }^{\circ} \mathrm{C}$ was chosen to avoid residual thermal stresses at room temperature.

Cyano-acrylate adhesive (Loctite 495) is used to attach the piezo disc to the glass. Then the connecting nipples for the inlet and outlet tubes as well as the electrical connections are attached. In order to fill the micropump, it is submerged in water in a bell jar. The air in the micropump is then removed by evacuation. When air is admitted into the bell jar, the micropump is filled with water. Figure 6(b) shows a photograph of the completely assembled pump with three valves. Table 2 lists the characteristic dimensions and calculated values for the components of the pumps.

\section{TABLE 2}

Characteristic dimensions and calculated values

\begin{tabular}{|c|c|c|}
\hline Dimensions (mm) & Two-valve pump & Three-valve pump \\
\hline $\begin{array}{l}\text { Pump membrane diameter } \\
\text { Pump chamber depth } \\
\text { Valve diaphragm diameter: } \\
\text { Valves } 1 \text { and } 2 \\
\text { Valve } 3 \\
\text { Sealing ring inner and outer diam } \\
\text { Valves } 1 \text { and } 2 \\
\text { Valve } 3 \\
\text { Thickness valves } \\
\text { Thickness oxide film }\end{array}$ & $\begin{array}{l}1.2 \text { and } 1.5 \\
0.040 \\
0.001\end{array}$ & $\begin{array}{l}12.5 \\
0.105 \\
7 \\
6 \\
1.2 \text { and } 1.5 \\
4.3 \text { and } 5.0 \\
0.080 \\
0.001\end{array}$ \\
\hline \multicolumn{3}{|l|}{ Calculated values } \\
\hline $\begin{array}{l}\text { Volume stroke } \Delta V_{\text {piezo }}(1) \\
\text { Volume stroke } \Delta v_{\text {memb }}(2) \\
\text { Deflection } \delta \text { valves } 1 / 2(3) \\
\text { Deflection } \delta \text { valve } 3(3) \\
\text { Lost volume stroke } \Delta V_{\text {valve }}(4) \\
\text { Pre-tension valves } 1 \text { and } 2 \\
\text { Pre-tension valve } 3\end{array}$ & $\begin{array}{l}0.21 \mu \mathrm{l}(100 \mathrm{~V}) \\
0.083 \mu \mathrm{l} / \mathrm{mH}_{2} \mathrm{O} \\
13 \mu \mathrm{m} / \mathrm{mH}_{2} \mathrm{O} \\
22 \times 10^{-2} \mu \mathrm{l} / \mathrm{mH}_{2} \mathrm{O} \\
0.1 \mathrm{mH}_{2} \mathrm{O}\end{array}$ & $\begin{array}{l}0.30 \mu \mathrm{l}(125 \mathrm{~V}) \\
0.043 \mu \mathrm{l} / \mathrm{mH}_{2} \mathrm{O} \\
0.9 \mu \mathrm{m} / \mathrm{mH}_{2} \mathrm{O} \\
0.1 \mu \mathrm{m} / \mathrm{mH}_{2} \mathrm{O} \\
2.4 \times 10^{-2} \mu \mathrm{l} / \mathrm{mH}_{2} \mathrm{O} \\
0.6 \mathrm{mH}_{2} \mathrm{O} \\
2.5 \mathrm{mH}_{2} \mathrm{O}\end{array}$ \\
\hline
\end{tabular}

\section{Measurements and comparison with simulations}

The yield is measured with the aid of a glass capillary tube. The pressure at the outlet $p_{\text {out }}$ is obtained with the use of a water reservoir, see Fig. 7. This enables exceptionally small yields of the order of $\mu \mathrm{l} / \mathrm{min}$ to be measured accurately. The piezo disc is controlled with a block voltage with variable height, duration and frequency of the pulses.

Figure 8 presents the measured yield of the two-valve pump as a function of the pressure at the outlet, with a block voltage of $100 \mathrm{~V}$ and various frequencies. The simulated pump curves are also shown. The yield is therefore strongly dependent on the outlet pressure and decreases almost linearly 


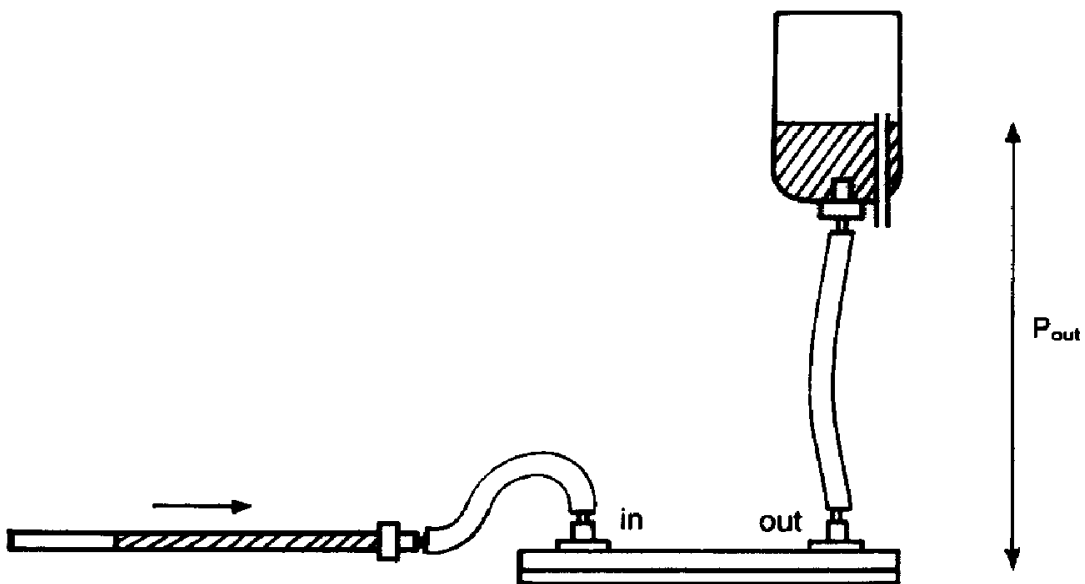

capillary tube

pump

Fig. 7. Measurement set-up.

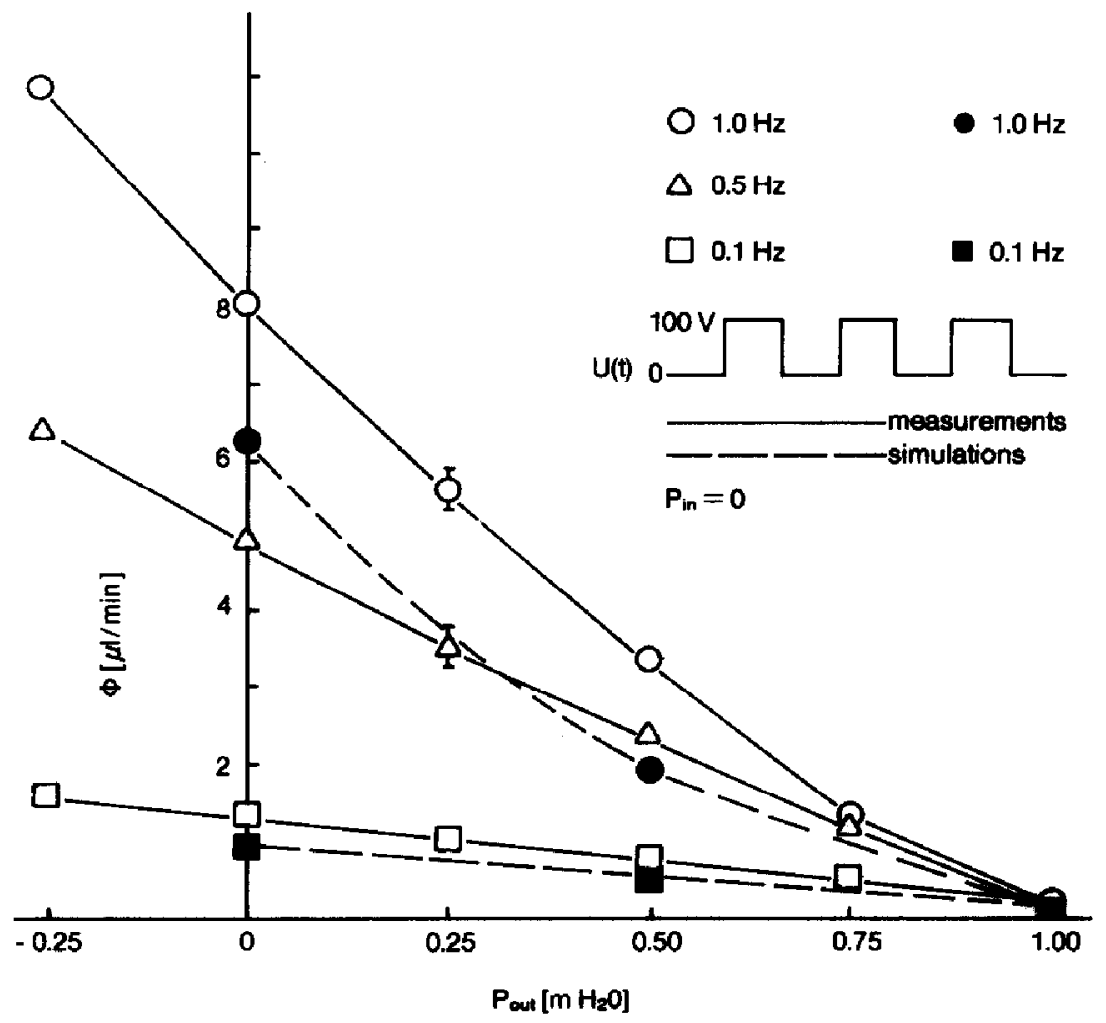

Fig. 8. Measurements and simulations of the two-valve pump.

with this pressure. In other measurements the yield appeared to increase linearly with the applied voltage at low frequencies, as expected.

If $p_{\text {out }}>p_{\text {in }}$, no liquid flow occurs from outlet to inlet, from which it can be concluded that the closure of the valves is very good. There is, however, a flow from inlet to outlet when there is sufficient excess pressure at the inlet. In order to characterize the operation of the valves, flow curves 
were measured. Figure 9 shows the flow through the valves as a function of the applied pressure difference $\Delta p$.

Measured and simulated pump curves of the three-valve pump are shown in Fig. 10. The applied voltage is $125 \mathrm{~V}$. The yield is now practically

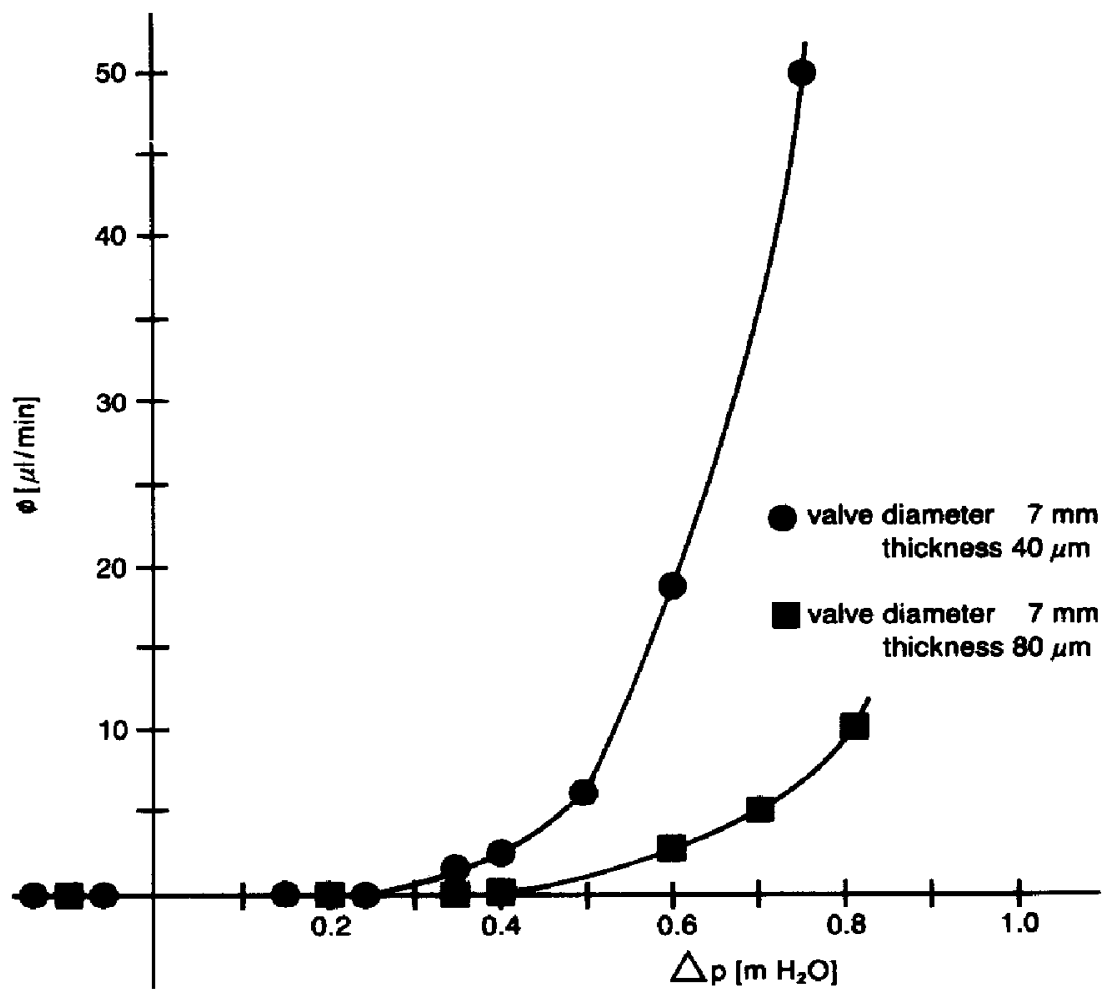

Fig. 9. Flow curves of single valves.

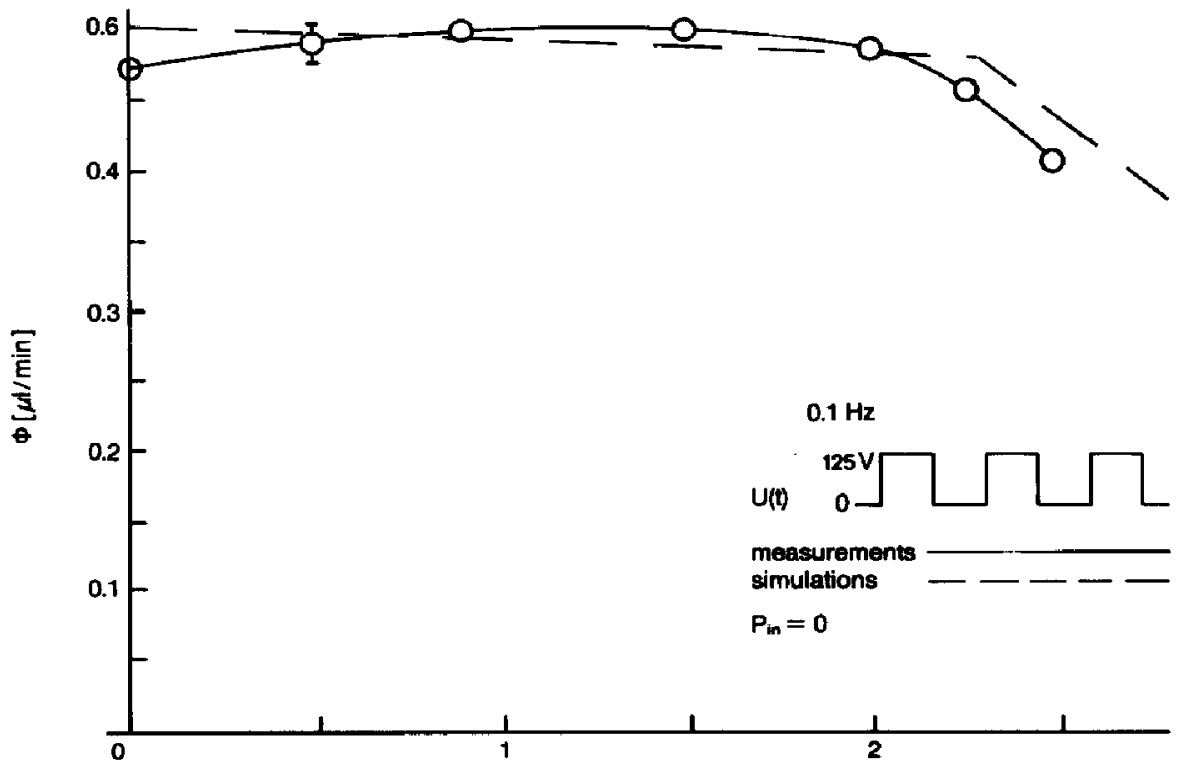

$P_{\text {out }}\left[\mathrm{m} \mathrm{H} \mathrm{H}_{2} \mathrm{O}\right]$

Fig. 10. Measurements and simulations of the three-valve pump. 
constant up to a pressure of $2 \mathrm{mH}_{2} \mathrm{O}$. For higher pressures, the third valve is continuously open and the pump behaviour resembles that of the two-valve pump. If the voltage is switched off, there is no flow in either direction whatever pressure may be applied at the inlet or outlet.

\section{Conclusion}

The described design of the three-valve pump, with a piezo disc/glass membrane actuator and three passive silicon diaphragm check valves, makes it possible to construct a pump with a pressure-independent yield and the flow blocked for any inlet or outlet pressure while the pump is switched off. The yield can be regulated by varying the applied block voltage in height and/or frequency. The results of the simulations are in good agreement with the measurements. It is therefore possible to design pumps having a specific pump characteristic. Leakage through closed valves appeared to be negligible.

\section{Current research}

We are currently investigating further miniaturization and integration, and the use of other physical principles for actuating the pump. Our goal is a pump that can be made out of silicon wafers by micromachining and using IC-related thin-film techniques. Instead of EDP as an etching agent, we now use a solution of potassium hydroxide and propanol in water. This solution is far less toxic and provides much cleaner working conditions.

\section{Acknowledgements}

The authors would like to thank Jan Smits, Ben Huizing, Rineke Groothengel, Jan Mulder, Theo Popma and Cock Harteveld for their help and contributions, and John Baxter, Katrina Emmett and Jan Fluitman for carefully reading the manuscript. This work was supported by the Centre for Microelectronics, Twente (CMET) and sponsored by Vitratron B.V. Dieren, the Netherlands.

\section{References}

1 K. E. Petersen, Silicon as a mechanical material, Proc. IEEE, 70 (1982) 420 - 457.

2 J. G. Smits, Piezoelectric micropump for peristaltic fluid displacements, NL patent 8302860 (1985).

3 S. Timoshenko and S. Woinowsky-Krieger, Theory of Plates and Shells, McGraw-Hill, New York, 2nd edn., 1950, pp. $51-72$.

4 S. Timoshenko and S. Woinowsky-Krieger, Theory of Plates and Shells, McGraw-Hill, New York, 2nd edn., 1950, pp. 364 - 377. 
5 J. J. Wortman and R. A. Evans, Young's modulus, shear modulus, and Poisson's ratio in silicon and germanium, J. Appl. Phys., 36 (1965) 153 - 156.

6 J. C. M. Mulder, Geintegreerde $\mathrm{Si} / \mathrm{ZnO}$ actuator voor micropomp, Master's Thesis, 060.0210 , University of Twente, Enschede, The Netherlands, 1984.

7 S. Bouwstra and T. S. J. Lammerink, Chemical etching of silicon for micromechanical devices, Proc. 3rd Sensors and Actuators Symp., The Netherlands, 30 - 31 October 1986, pp. 199 - 209.

8 G. Wallis and D. I. Pomerantz, Field assisted glass-metal sealing, J. Appl. Phys., 40 (1969) 3946 - 3949.

9 P. B. De Nee, Low energy metal-glass bonding, J. Appl. Phys., 40 (1969) 5396 - 5397.

\section{Biographies}

Harald van Lintel was born in Amsterdam, the Netherlands, in $1961 . \mathrm{He}$ received his Polytechnic diploma in applied physics from the Enschede Polytechnic, Enschede, the Netherlands, in 1983. In 1984 he joined the Centre for Microelectronics Twente, where his research was focused on micromechanical sensors and actuators. He has decided to take sabbatical leave, and is currently enjoying a trip around the world.

Frans C. M. van de Pol was born in Apeldoorn, the Netherlands, in 1953. He has a diploma in civil engineering and a university degree in chemistry. In 1985 he joined the group Transducers and Materials Science at the University of Twente. He is investigating the possibilities of realizing an integrated micropump.

Siebe Bouwstra was born in Amsterdam, the Netherlands, in 1958. He received his M.Sc. degree in mechanical engineering from the University of Twente, Enschede, the Netherlands, in 1984. In the same year he joined the Sensors and Actuators Research Group at the University of Twente, where his research is focused on micromechanical resonant sensors and actuators. 